\title{
SEMEN QUALITY AND REPRODUCTIVE ENDOCRINAL FUNCTION WITH REGARD TO BLOOD LEAD LEVEL IN INFERTILE PAINTERS
}

\author{
By \\ Mansour NA*,Hosni $\mathrm{H}^{* *}$, Shatta MM*** and Azab ShS**** \\ *Dept. Of Occupational \&Environmental Medicine ** Dept. Of Andrology \\ *** Dept. Of Chemical Pathology, Faculty of Medicine, Cairo University \\ **** Dept. Of Urosurgery, $6^{\text {th }}$ October University
}

\begin{abstract}
:
Objective: To investigate the effect of lead on semen quality and reproductive endocrinal function among infertile painters. Methods: A retrospective cohort study was performed using data collected from 27 infertile painter recruited through infertility clinic and Andrology inpatient department. All participants were subjected to semen analysis, measuring of blood lead level ( $\mathrm{BPb}$ ) and serum level of endocrinal parameters including follicle-stimulating hormone(FSH), luteinizing hormone( $\mathrm{LH})$, testosterone(T) and prolactin (pl). Results:-significant decline in the spermatic count and motility in those with longer duration of exposure $(\geq 15 \mathrm{y})$ without significant duration influence on $\mathrm{BPb}$ and serum level of FSH, LH, PT and T. In addition, significant negative correlation of $\mathrm{BPb}$ and spermatic count and motility was found, while all endocrinal parameters showed non-significant correlation. Further analysis of the results revealed statistically significant decline in spermatic motility and increase in testosterone level among the group of $\mathrm{BPb} \geq 20 \mu \mathrm{g} / \mathrm{dl}$ beside the observed reduction in the count, which did not reach the significant level. While other endocrinal parameters showed non statistically significant differences. In conclusion, infertile painters were at risk of Lead related influence on semen quality specially spermatic motility and increased testosterone level without significant affection of other reproductive endocrinal parameters.
\end{abstract}

Key words: Lead, infertile painters, semen analysis, BPb, FSH, LH, T, pl 


\section{Introduction}

The danger to public health from lead $(\mathrm{Pb})$ exposure continues to be a matter of concern. Early clinical features of lead toxicity are non-specific and an occupational history is particularly valuable.

Lead in the body comprises $2 \%$ in the blood (its half life[t1/2]35 days) and 95\% in bone and dentine (t1/2 20-30 years). Blood lead may remain elevated for years after cessation from long exposure due to redistribution from bone. Therefore, blood lead concentration $(\mathrm{BPb})$ is the most widely used marker for inorganic lead exposure(Gordon et al,2002). the World Health Organization define a $\mathrm{BPb}$ of 40 micrograms/ $\mathrm{dl}$ as the threshold of concern in adults and a level of 10 micrograms/ dl in young children. However, recent studies have reported the possibility of adverse health effects at a lower BPb levels suggesting that there is no safe level of exposure(Wakefield 2002).

Lead exposure could be through contaminated food, water, and house dust and through industrial activities such as metal recycling and the battery industry .Also painters are a group with potentially high exposure. In the United States, for example, although the use of $\mathrm{Pb}$ in house paint peaked in 1940 and was banned in
$1978,40 \%$ of the nation's housing stock is estimated to still contain $\mathrm{Pb}$-based paint (Wakefield 2002).

A significant increase in the incidence of male infertility has been described in the international literature, raising questions about its causes. This can be connected to growing exposure to combined occupational and environmental toxins. Human and animal evidence suggests that $\mathrm{Pb}$ may have adverse impacts on male reproductive health at relatively low levels( Jurasovic et al. 2004; Telisman et al. 2007).

The mechanism by which lead exerts toxic effects on testis is quite complex. It involves spermatogenesis, steroidogenesis, and red-ox system. Pb may adversely affect sperm shape, motility, and DNA integrity (Eibensteiner et al. 2005; HernandezOchoa et al. 2005). Chronic lead exposure can induce morphological disorder by decreasing testicular weight, seminal vesicle, peritubular fibrosis, decrease in seminiferous tubular diameter and decreasing in germ cell population related to an apoptotic process (Martynowicz et al,2005).Also Queiroz and Waissmann,2006 postulated that $\mathrm{Pb}$ may cause functional disorder by acting on the endocrine system as an endocrinal disruptor. 


\section{Objective}

To investigate the effect of lead on semen quality and reproductive endocrinal function among infertile paint workers.

\section{Subjects \& Methods}

\section{Subjects recruitment}

A retrospective cohort study was performed using data collected from twenty seven recently married(<3years) infertile painter who had an abnormal seminal profile on the basis of their prior semen analysis.

All workers were recruited through Kasr Al-Aini infertility clinic and Andrology inpatient department.

The study population consisted of twenty-four painter with oligo-asthenoteratospermia (sperm of low concentration, reduced motility and increased abnormal morphology) and three azoospermic. All were matched as regard age and socioeconomic standard.

We excluded those with known causes of infertility as genetic disorders related to fertility, testicular cancer and bilateral orchidectomy or taking hormone therapy. Informed consent was obtained from all participants.

\section{Methods}

Full history taking with emphasis on occupational exposures, usage of protective equipment and lifestyle habits was retrospectively obtained through personal interviews.

All participants were subjected to medical examination, semen analysis, measuring of blood lead level( $\mathrm{BPb})$ and serum level of endocrine parameters including follicle-stimulating hormone (FSH), luteinizing hormone (LH), testosterone $(\mathrm{T})$ and prolactin( $\mathrm{pl})$.

\section{Semen parameters}

Semen samples were collected and analysed using the World Health Organization protocol (WHO 1999). Sperm morphology was evaluated according to Kruger's strict criteria (Kruger et al. 1988).

\section{Measurement of blood lead level}

Whole venous blood was collected into tubes containing EDTA .Samples were assayed for $\mathrm{Pb}$ using atomic absorption spectrophotometer (A ANALYST 800 atomic absorption Perkin-Elmer).

Its principle depend on the fact that the electrons of the atoms in the atomizer can be promoted to higher orbitals for a short amount of time by absorbing a set quantity of energy (i.e. light of a given wavelength). 
This amount of energy (or wavelength) is specific to a particular electron transition in a particular element, and in general, each wavelength corresponds to only one element. This gives the technique its elemental selectivity.

As the quantity of energy (the power) put into the flame is known, and the quantity remaining at the other side (at the detector) can be measured, it is possible, from BeerLambert law, to calculate how many of these transitions took place, and thus get a signal that is proportional to the concentration of the element being measured.

\section{Measurement of endocrinal parameters}

LH, FSH, PL and testosterone levels were determined in serum by using enzyme immunoassay (EIA), LH, FSH and PL were assayed on Immulite 2000. Its principle is solid phase, two site chemiluminescent immunometric assay while testosterone was assayed using state-of-art Elecsys-2010, its principle is electrochemiluminescence immunoassay.

\section{Statistical analysis}

We performed data analysis using SPSS program version 9.1. Blood lead levels, semen-quality parameters and reproductive endocrinal parameters were expressed as mean and standard deviation(SD).We classified our participants into groups using the median of duration of exposure $(=15)$ and the nearest available $\mathrm{BPb}$ level $(=20)$ to the threshold of concern.

Student $t$ test was used for analysis of quantitative data between groups. Relations between $\mathrm{BPb}$ and different parameters were tested statistically using pearson correlation coefficient.

\section{Results}

The study population consists of 27 primary infertile painters. The range of age was [27 - 39] years with mean value 31.37 +4.89 .The duration of work ranged from 3 years up to 20 years with mean duration $11.89+6.08$.The frequency of paint stripping can not be determined. Smoking index (number of pack per day $\mathrm{X}$ number of smoking years) ranged from 0 up to 30 pack. years with mean value $10.38+11.24$. Medical examination revealed two cases with bilateral small to moderate reduction in testicular size.

Concerning semen analysis of the studied group, there was obvious reduction in the spermatic count and motility with increasing in abnormal form. On the other hand all reproductive and endocrinal parameters were within normal range. Blood lead level was below the threshold of concern $[<40 \mu \mathrm{g} / \mathrm{dl}]$ ( Table 1). 
As regard smoking, we divided our studied workers into two groups( Table 2).The result of semen analysis and reproductive endocrinal parameters showed a statistically significant decline in spermatic motility, abnormal forms and serum prolactin level in the smokers group. Also, it is noticed that the blood lead level was higher in the smoker group but the difference was not to the significant level

Concerning the duration of exposure, the studied group was divided into two groups, the first group with duration $>$ 15 years $[n=13]$ and the second one with duration $<15$ years $[n=14]$. Table 3 reveals statistically significant decline in the count and motility in those with longer duration of exposure without significant duration influence on $\mathrm{BPb}$ and serum level of FSH, LH, PL and T.
Correlation coefficients of blood lead levels in relation to the age, smoking index(SI), duration of work, semen analysis and reproductive endocrinal parameter were shown in ( Table 4). Significant negative correlation was founded regarding spermatic count and motility but all endocrinal parameters showed non significant correlation.

Further, the exposed group was divided into $\mathrm{BPb}>20 \mu \mathrm{g} / \mathrm{dl}[\mathrm{n}=11]$ and $<20 \mu \mathrm{g} /$ dl $[n=16]$. It was demonstrated that ( Table 5) there was statistically significant decline in spermatic motility and increase in testosterone level among the group of $\mathrm{BPb}$ $>20 \mu \mathrm{g} / \mathrm{dl}$ beside the observed reduction in the count, which did not reach the significant level. While other endocrinal parameters showed non statistically significant difference. 
TABLE (1) Semen analysis, reproductive endocrinal parameters and blood lead level of the studied grou

\begin{tabular}{|c|c|c|c|}
\hline & Minimum & maximum & mean \pm SD \\
\hline Abstance period (days) & 3 & 5 & $4.51 \pm 0.70$ \\
\hline Volume (ml) & 2 & 3.5 & $2.59 \pm 0.58$ \\
\hline Count (million) & 0 & 6 & $1.77 \pm 2.19$ \\
\hline Motility (\%) & 0 & 60 & $24.26 \pm 20.65$ \\
\hline Progressive motility (\%) & 0 & 5 & $0.005 \pm 0.01$ \\
\hline Abnormal form (\%) & 0 & 98 & $74.52 \pm 40.64$ \\
\hline FSH (mIU/ ml) & 1.21 & 12.50 & $5.40+3.90$ \\
\hline LH (mIU/ ml) & 3.30 & 6.50 & $5.32+1.00$ \\
\hline Prolactin $(\mathrm{ng} / \mathrm{ml})$ & 4.20 & 12.20 & $7.38+2.59$ \\
\hline Testosterone $(\mathrm{ng} / \mathrm{ml})$ & 3.10 & 13.30 & $7.97+3.96$ \\
\hline Lead $(\mu \mathrm{g} / \mathrm{dl})$ & 3.40 & 30.80 & $15.37+7.81$ \\
\hline
\end{tabular}

TABLE ( 2 ) Semen analysis, endocrinal parameters and blood lead level in relation to smoking.

\begin{tabular}{|c|c|c|c|c|}
\hline & Smoker & Non-smoker & \multirow{2}{*}{$\mathrm{t}$} & \multirow{2}{*}{$\mathrm{p}$} \\
\cline { 2 - 3 } & mean $\pm \mathrm{SD}$ & mean $\pm \mathrm{SD}$ & & \\
\hline No. & 17 & 10 & & \\
\hline Duration ( years ) & $11.65 \pm 6.93$ & $12.30 \pm 4.62$ & -0.29 & $>0.05$ \\
\hline Count (million) & $1.86 \pm 2.59$ & $1.62 \pm 1.38$ & 0.3 & $>0.05$ \\
\hline Motility $(\%)$ & $17.35 \pm 19.77$ & $36.00 \pm 17.13$ & -2.57 & $<0.05^{*}$ \\
\hline $\mathrm{Ab}$ form $(\%)$ & $62.71 \pm 47.75$ & $94.00 \pm 2.50$ & -2.57 & $<0.05^{*}$ \\
\hline $\mathrm{FSH}(\mathrm{mIU} / \mathrm{ml})$ & $5.15 \pm 3.44$ & $6.68 \pm 5.17$ & -0.83 & $>0.05$ \\
\hline LH $(\mathrm{mIU} / \mathrm{ml})$ & $5.34 \pm 0.71$ & $5.30 \pm 1.42$ & 0.07 & $>0.05$ \\
\hline Prolactin $(\mathrm{ng} / \mathrm{ml})$ & $6.46 \pm 1.89$ & $8.95 \pm 2.96$ & -2.38 & $<0.05^{*}$ \\
\hline Testosterone $(\mathrm{ng} / \mathrm{ml})$ & $8.62 \pm 3.59$ & $6.88 \pm 4.51$ & 1.04 & $>0.05$ \\
\hline Lead $(\mu \mathrm{g} / \mathrm{dl})$ & $17.45 \pm 8.57$ & $12.96 \pm 5.64$ & 1.64 & $>0.05$ \\
\hline
\end{tabular}

*Statistical significanceat $\mathrm{P}<0.05$ 
TABLE(3) Semen analysis, endocrinal parameters and blood lead level, in relation to duration of exposure.

\begin{tabular}{|c|c|c|c|c|}
\hline & Duration => 15 & Duration $<$ 15 & \multirow{2}{*}{$\mathrm{t}$} & \multirow{2}{*}{$\mathrm{p}$} \\
\cline { 2 - 3 } & mean \pm SD & mean \pm SD & & \\
\hline No. & 13 & 14 & & \\
\hline Count (million) & $0.93 \pm 1.23$ & $2.57 \pm 2.62$ & -2.11 & $<0.05^{*}$ \\
\hline Motility $(\%)$ & $20.77 \pm 20.19$ & $27.50 \pm 21.28$ & -0.84 & $<0.05^{*}$ \\
\hline Ab_form & $73.62 \pm 42.02$ & $75.36 \pm 40.88$ & -0.11 & $>0.05$ \\
\hline FSH $(\mathrm{mIU} / \mathrm{ml})$ & $6.44 \pm 4.09$ & $4.45 \pm 3.62$ & 1.33 & $>0.05$ \\
\hline LH $(\mathrm{mIU} / \mathrm{ml})$ & $5.04 \pm 1.19$ & $5.59 \pm 0.75$ & -1.42 & $>0.05$ \\
\hline Prolactin $(\mathrm{ng} / \mathrm{ml})$ & $7.82 \pm 2.66$ & $6.99 \pm 2.57$ & 0.82 & $>0.05$ \\
\hline Testosterone $(\mathrm{ng} / \mathrm{ml})$ & $7.08 \pm 3.09$ & $8.88 \pm 4.56$ & -1.25 & $>0.05$ \\
\hline Lead $(\mu \mathrm{g} / \mathrm{dl})$ & $17.37 \pm 8.8$ & $14.32 \pm 6.68$ & 1.01 & $>0.05$ \\
\hline
\end{tabular}

TABLE(4)Pearson correlation of blood lead level in relation to semen analysis \& endocrinal parameters

\begin{tabular}{|c|c|c|}
\hline & $\mathbf{r}$ & $\mathbf{p}$ \\
\hline Age & 0.03 & $>0.05$ \\
\hline Smoking index ( Pack.Year) & 0.35 & $>0.05$ \\
\hline Duration ( years) & 0.15 & $>0.05$ \\
\hline Count (million) & -0.47 & $<0.05^{*}$ \\
\hline Motility (\%) & -0.55 & $<0.05^{*}$ \\
\hline Abnormal form & 0.12 & $>0.05$ \\
\hline FSH (mIU/ ml) & -0.23 & $>0.05$ \\
\hline LH (mIU/ ml) & -0.29 & $>0.05$ \\
\hline Prolactin (ng/ ml) & -0.27 & $>0.05$ \\
\hline Testosterone (ng/ml) & 0.36 & $>0.05$ \\
\hline
\end{tabular}


TABLE ( 5 ) Semen analysis \& endocrinal parameters in relation to blood lead level

\begin{tabular}{|c|c|c|c|c|}
\hline & Lead => 20 & Lead $<\mathbf{2 0}$ & \multirow{2}{*}{$\mathrm{t}$} & $\mathrm{p}$ \\
\cline { 2 - 3 } & mean $\pm \mathrm{SD}$ & mean $\pm \mathrm{SD}$ & & \\
\hline No. & 11 & 16 & & \\
\hline Duration ( years) & $12.27 \pm 5.55$ & $11.63 \pm 6.59$ & 0.27 & $>0.05$ \\
\hline Count (million) & $1.17 \pm 2.07$ & $2.19 \pm 2.25$ & -1.2 & $>0.05$ \\
\hline Motility (\%) & $13.64 \pm 0.80$ & $31.56 \pm 23.57$ & -2.81 & $<0.05^{*}$ \\
\hline Ab_form (\%) & $79.91 \pm 39.51$ & $70.81 \pm 42.26$ & 0.57 & $>0.05$ \\
\hline FSH (mIU/ml) & $4.41 \pm 2.52$ & $6.10 \pm 4.59$ & -1.22 & $>0.05$ \\
\hline LH (mIU/ ml) & $5.06 \pm 0.71$ & $5.50 \pm 1.15$ & -1.21 & $>0.05$ \\
\hline Prolactin $(\mathrm{ng} / \mathrm{ml})$ & $6.44 \pm 1.51$ & $8.03 \pm 3.00$ & -1.8 & $>0.05$ \\
\hline Testosterone $(\mathrm{ng} / \mathrm{ml})$ & $9.75 \pm 3.50$ & $6.76 \pm 3.90$ & 2.07 & $<0.05^{*}$ \\
\hline
\end{tabular}

*Statistically significant

\section{Discussion}

Male factor has been considered a major contributory factor to infertility. The underlying pathogenetic mechanisms can reflect the effect of systemic disorders, like hypothalamic-pituitary disease, testicular cancers, germ cell aplasia and genetic factors. Oligo-asthenoteratospermia of unknown cause is common (Vandekerckhove P et al,2000) specially if passed without detailed occupational history. There is a list of occupational and environmental toxins, which are categorised as a reproductive disruptor including pesticides, glycol ethers, and metals such as cadmium ,copper, molybdenum, and lead (Skakkebaek N.E. et al 1994).

Research conducted in recent years has increased public health concern about the reproductive and endocrinal toxicity of lead even at low dose. Multiple sperm parameters are affected as lead levels rise contributing to the production of unexplained male infertility (Benoff $\mathrm{S}$ et al,2003). Naha and Manna in 2007 reported that Occupational lead exposure caused several types of male reproductive impairments in different working populations. 
Painters are a group of workers with potentially high exposure to lead and organic solvents during its handling (IARC,1989). Workers were exposed to lead during painting or during sanding of old lead containing layers of paint. The dangers of lead exposure in workers who strip paint in old buildings should be taken in our considerations, as it is potential source of intoxication (Hart et al,1996 and Marino et al,1990). So it is important to highlight the importance of taking a full occupational history.

Lead is known to reduce fertility in animal models, but a direct link between lead exposure and human infertility has not yet been established (Benoff $S$ et al 2003) and this is what our study aimed at.

Still, some selection bias (e.g. solvents exposure, smoking, alcohol ... ) cannot be ruled out, as our study focused on infertile painter.

Smoking and alcohol cause impairment in semen quality(Gwendoline de Fleurian et al 2009).Cigarette smoking enhances the levels of $\mathrm{Cd}$ and $\mathrm{Pb}$ in seminal plasma and blood. Also smoking increases the extent of oxidative damage with reduction of the antioxidant defences in the sperm of infertile males( Kiziler AR et al,2007).This can explain our result of significant impairment in sperms motility and higher $\mathrm{BPb}$ level among smokers although it doesn't reach the significant level. As all azoospermic participant(with $0 \%$ abnormal forms) were smokers ,the significance decrease of abnormal forms in them was noticed. Also, smoking has reproductive endocrinal effect. Jurasovi $\mathbf{J}$ et al in 2004 found that smoking was significantly associated with a decrease in serum prolactin, which support our finding.

The fraction of $\mathrm{Pb}$ that is absorbed depends mainly on the physical and chemical form, particularly particle size and the solubility of the specific compound. Other important factors are specific to the exposed subject, such as age, sex, nutritional status, genetic background and duration of exposure(ATSDR 1999; National Research Council 1993).

Analysis of the results regarding the duration of exposure revealed significant reduction in spermatic count and motility in those with longer occupational duration $(n=13)$ without significant increase of $\mathrm{BPb}$ in them. While no statistically significant difference was noticed between the two groups in the serum level of FSH,LH and PL. The independent roles of exposure duration and effect modification by other confounders like smoking and solvents exposure may have been difficult to distinguish( Sallmn M et al,2001). 
It is difficult to assume that the observed impairment in semen parameters are entirely attributable to lead exposure. Although lead is important element of paints, there are other chemicals in these products, which could have been responsible for our findings like organic solvents such as petroleum solvents, toluene, xylene, ketones, alcohols, esters, and glycol ethers (IRAC,1989)during handling of paints, thinners, and cleansers. Organic solvents can pass the blood-testis barrier, so they have adverse reproductive effects including semen abnormalities ( Lindbohm M L et al 1999). Cherry $\mathrm{N}$ et al in 2008 reported that Glycol ether exposure was related to low motile sperm count in men attending fertility clinics.

At the present exposure level, lead might cross blood-testis-barrier and increased its value in semen of the occupationally exposed paint factory workers, thereby producing detrimental effects on semen quality and sperm characteristics(Naha N \& Manna B 2007).So the negative correlation in our research between $\mathrm{BPb}$ and spermatic count and motility suggests the necessity of biological monitoring by regular measuring of $\mathrm{BPb}$ level with the intention to prevent excessive occupational exposure.

Lead not only affects the spermatic count, but also damages the sperm structure and membrane integrity, motility and functional activity among the battery and paint factory workers(Naha N\& Chowdhury $\mathrm{AR}$,2006). Even lower $\mathrm{PbB}(<50 \mu \mathrm{g} / \mathrm{dl})$ is associated with male infertility( Apostoli P et al,2000).

In the current work, there was significant reduction in spermatic motility in those with $\mathrm{BPb}>20 \mu \mathrm{g} / \mathrm{dl} \quad(\mathrm{n}=11)$ while no statistically significant difference was reported as regard spermatic count and abnormal form in the same group. Viskum $S$ et al in 1999, reported that occupational lead exposure at currently acceptable levels has a small adverse effect on sperm quality, especially sperm motility. Other reports suggested moderate exposures to $\mathrm{Pb}(\mathrm{BPb}$ $<40 \mu \mathrm{g} / \mathrm{dl}$ ) can significantly reduce human semen quality without conclusive evidence of impairment of male reproductive endocrine function(Apostoli P et al,2000).

Although our results regarding FSH,LH, PL and T showed non significant correlations with $\mathrm{BPb}$ level, the positive correlation with testosterone was noticed. On the other hand, our results showed statistically significant increase in the testosterone level in the group with $\mathrm{BPb}>$ $20 \mu \mathrm{g} / \mathrm{dl}$ suggesting that lead may target Leydig cell function specially at a higher level. No statistically significant difference was noticed between the same two groups as regard the level of FSH,LH and PL. These are consistent with the results 
of Telisman et al(2000) who studied semen quality and reproductive endocrine function in relation to lead and found a significant increase in serum testosterone and estradiol without $\mathrm{Pb}$ related influence on FSH,LH and PL in serum. Also, Telisman S et al(2007) mentioned that lead was significantly positively associated with testosterone. More over Allouche L and co workers(2009) studied the Chronic effects of low lead levels on sperm quality, gonadotropins and testosterone in albino rats and concluded that sperm parameters were altered at low or moderate lead concentrations with no obvious alteration of hypothalamic-pituitary function and the increased testosterone level suggested that lead may target testicular function.

Contrary to our result, concerning testosterone, Naha N \& Manna B(2007) mentioned that deterioration of sperm count, structural abnormality of spermatozoa and sperm head DNA hyploidy was associated with high blood lead levels in the paint factory workers without interfering serum FSH, LH and testosterone level.

Beside, it was reported that lead act on the endocrine system as an endocrinal disruptor resulting in decrease of testosterone synthesis(Queiroz andWaissmann,2006).

Despite the controversial findings of the available researches, we should consider that not only the altered/disturbed concentrations of gonadotrophins and androgenic hormones are responsible for male sub-fertility but also the disturbances in gonadotrophic: androgenic hormones ratios lead to infertility since these all hormones act synergistically( Khan MS et al,2008).

Regarding prolactin level in serum, although our finding showed that there was no statistically significant difference, its level was lower in those with $\mathrm{BPb}>20$ $\mu \mathrm{g} / \mathrm{dl}$. Telisman $\mathrm{S}$ et al(2007) studied reproductive toxicity of low-level lead exposure in men and found a significant lead-related decrease in serum prolactin.

There is a debate regarding lead and male infertility: Mendiola J et al(2008) studied exposure to environmental toxins including lead in males seeking infertility treatment and concluded that male infertility in patients attending infertility clinics may often be the result of occupational lead exposure. On the other hand, Gracia CR and his colleagues(2005) studied occupational exposures to lead and male infertility and found no significant associations were noted between infertility and exposure to metal fumes, solvents, lead and paint. They concluded that no clear clinically important associations between occupational exposures to lead and male infertility could be identified in this study. 
In conclusion, infertile painters with potentially high occupational exposure to lead, although of its relatively low level, were at risk of lead related influence on semen quality specially spermatic motility and increased testosterone level without significant affection of other reproductive endocrinal parameters.

However, some confounding attributable to personal and exposure conditions of the workers cannot be ruled out, in addition of small size of the study, so it is not easy to assert or to deny the effect of lead on infertile painter.

Additional human epidemiologic studies, as well as mechanistic studies with better controlling for potential confounders are needed. We also recommend a properly planed programme for health promotion of painters that include health education with stressing on the value of personal protective equipment, medical examination and regular $\mathrm{BPb}$ monitoring with highlighting the emerging concept of reducing the threshold of its concern.

\section{References}

1. Allouche L, Hamadouche M and Touabti A (2009) : Chronic effects of low lead levels on sperm quality, gonadotropins and testosterone in albino rats. Exp Toxicol Pathol, 61(5): 50310.

2. Apostoli P, Bellini A, Porru S and Bisanti L ( 2000 ) : The effect of lead on male fertility: a time to pregnancy (TTP) study. Am J Ind Med, 38(3): 310-5.
3. ATSDR ( 1999 ) : Toxicological Profile for Lead. Atlanta, GA:Agency for Toxic Substances and Disease Registry

4. Benoff S, Centola GM, Millan C, Napolitano B, Marmar JL and Hurley IR ( 2003 ) : Increased seminal plasma lead levels adversely affect the fertility potential of sperm in IVF. Hum Reprod, 18(2): 374-83

5. Cherry N, Moore H, McNamee R, Pacey A, Burgess G, Clyma JA, Dippnall M, Baillie H and Povey A ( 2008 ) : Occupation and male infertility: glycol ethers and other exposures. Occup Environ Med, 65(10): 708-14.

6. Eibensteiner L, Del Carpio Sanz A, Frumkin H, Gonzales C and Gonzales GF. ( 2005 ) : Lead exposure and semen quality among traffic police in Arequipa, Peru. Int J Occup Environ Health. 11:161-166.

7. Gracia CR, Sammel MD, Coutifaris C, Guzick DS and Barnhart KT ( 2005 ) :Occupational exposures and male infertility. Am J Epidemiol, 162(8): 729-33.

8. Gordon J N , Taylor A and Bennett P N (2002) : Lead poisoning, case studies. Br J Clin Pharmacol. 53(5): 451-458.

9. Gwendoline de Fleurian, Jeanne Perrin, René Ecochard ,etal ( 2009 ) : Use of a Questionnaire to Correlate Self-Reported Occupational Risk Factors and Semen Quality in Clinical Practice, DOI:10.2164/jandrol.108.005918

10. Hart SP, McIver B, Frier BM and Agius RM.( 1996 ):Abdominal pain and vomiting in a paint stripper. Postgrad Med J.72:253-255.

11. Hernandez-Ochoa I, Garcia-Vargas G, LopezCarrillo L, Rubio-Andrade M, Moran-Martinez J, Cebrian ME, et al. ( 2005 ) : Low lead environmental exposure alters semen quality and sperm chromatin condensation in northern Mexico. Reprod Toxicol. 20:221-228.

12. IARC. (1989): Some organic solvents, resin monomers and related compounds, pigments and occupational exposures in paint manufac- 
ture and painting. IARC Monographs on the evaluation of carcinogenic risks to humans vol. 47. Lyon, France: International Agency for Research on Cancer.

13. Khan MS , Ali I , Tahir F and Khan GM (2008) : Simultaneous analysis of the three hormones involved in spermatogenesis and their interrelation ratios. Pak J Pharm Sci, 21(4): 344-9.

14. Marino PE, Landrigan PJ, Graef J, et al ( 1990) : A case report of lead paint poisoning during renovation of a Victorian farmhouse. Am J Public Health. 80:1183-1185.

15. Lindbohm M L. (1999): Effects of occupational solvent exposure on fertility. Scand J Work Environ Health 25(suppl 1)44-46.

16. Martynowicz H , Andrzejak R and Medra! > M ( 2005 ) : The influence of lead on testis function. Med Pr, 56(6): 495-500

17. Mendiola J , Torres-Cantero AM, Moreno-Grau JM, Ten J , Roca M , Moreno-Grau S and Bernabeu R ( 2008 ) : Exposure to environmental toxins in males seeking infertility treatment: a case-controlled study. Reprod Biomed Online, 16(6): 842-50.

18. Naha $\mathrm{N}$ and Chowdhury AR ( 2006 ) : Inorganic lead exposure in battery and paint factory: effect on human sperm structure and functional activity. J UOEH, 28(2): 157-71.

19. Naha N and Manna B (2007 ) : Mechanism of lead induced effects on human spermatozoa after occupational exposure. Kathmandu Univ Med J (KUMJ), 5(1): 85-94.

20. National Research Council (1993): Measuring Lead Exposure in Infants Children and other Sensitive Populations. Washington, DC:National Academy Press.

21. Jurasovi J, Cvitkovi P, Pizent A, Colak B and Telisman S (2004) : Semen quality and reproductive endocrine function with regard to blood cadmium in Croatian male subjects. Biometals, 17(6): 735-43

22. Kiziler AR, Aydemir B, Onaran I, Alici B, Oz- kara H, Gulyasar T and Akyolcu MC ( 2007 ) : High levels of cadmium and lead in seminal fluid and blood of smoking men are associated with high oxidative stress and damage in infertile subjects. Biol Trace Elem Res, 120(1-3): 82-91

23. Queiroz EK and Waissmann W ( 2006 ) : Occupational exposure and effects on the male reproductive system. Cad Saude Publica, 22(3): 485-93.

24. Skakkebaek N.E., Giwercman A. and de Kretser D ( 1994 ) : Pathogenesis and management of male infertility. Lancet. 343:1473-1479.

25. Telisman S, Colak B, Pizent A, Jurasovic J and Cvitkovic P. ( 2007 ) : Reproductive toxicity of low-level lead exposure in men. Environ Res. 105:256-266.

26. Telisman S, Cvitković P, Jurasović J , Pizent A, Gavella M , and Rocić B ( 2000 ) : Semen quality and reproductive endocrine function in relation to biomarkers of lead, cadmium, zinc, and copper in men.Institute for Medical Research and Occupational Health, Zagreb, Croatia. Environ Health Perspect.; 108(1): 45-53.

27. Templeton A., Fraser C. and Thompson B. ( 1990 ) : The epidemiology of infertility in Aberdeen. BMJ. 301:148-152.

28. Vandekerckhove P, Lilford R, Vail A and Hughes E ( 2000 ) : Clomiphene or tamoxifen for idiopathic oligo/asthenospermia. Cochrane Database Syst Rev, (2): CD000151

29. Viskum S , Rabjerg L, J rgensen PJ and Grandjean P ( 1999 ) : Improvement in semen quality associated with decreasing occupational lead exposure. Am J Ind Med, 35(3): 257-63.

30. Wakefield J.( 2002 ) : The lead effect. Environ Health Perspect.110:A574-A580.

31. WHO (World Health Organization) ( 1999 ) : WHO Laboratory Manual for the Examination of Human Semen and Sperm-Cervical Mucus Interaction. 4. New York: Cambridge University Press. 